\title{
Antigen Nonspecific Effect of Major Histocompatibility Complex Haplotype on Autoantibody Levels in Systemic Lupus Erythematosus-prone Ipr Mice
}

\author{
Philip L. Cohen, Elizabeth Creech, Danièle Nakul-Aquaronne, Richelle McDaniel, Scott Ackler, \\ Rebecca G. Rapoport, Eric S. Sobel, and Robert A. Eisenberg \\ Departments of Medicine and Microbiology/Immunology, University of North Carolina School of Medicine, \\ Chapel Hill, North Carolina 27599-7280
}

\begin{abstract}
MHC-linked genes strongly influence susceptibility to autoimmune diseases and also regulate responses to exogenous antigens. To begin to understand the mechanism of this MHC effect on disease, we have investigated MHC-congenic mouse strains that develop spontaneous autoimmunity because of the lpr gene. C57BL6/lpr (B6/lpr) mice (H-2 $\left.{ }^{b}\right)$ are known to have substantial levels of autoantibodies to chromatin, single stranded DNA (ssDNA ${ }^{3}$ ), and IgG of different murine subclasses (rheumatoid factor). We have crossed the $\mathrm{H}-2^{\mathrm{d}}$ and the H-2 ${ }^{\text {bm12 }}$ (la mutant) haplotypes onto the B6/lpr background. Surprisingly, levels of all of the autoantibodies were markedly lower in B6/lpr.H-2d, but levels in B6/lpr.H-2 ${ }^{\text {bm12 }}$ were no different from those in $\mathrm{B} 6 / \mathrm{lpr}$ mice. The downregulating influence of the $\mathrm{H}-2^{\mathrm{d}}$ allele was dominant, and there was no effect on autoantibody fine specificities. The genetics of the $\mathrm{H}-2^{\mathrm{d}}$ effect and its diffuse influence on multiple autoantibody specificities, in addition to the lack of effect of the bm12 mutation, which modifies the peptide-binding groove of I-A, together raise the question of whether MHC-linked genes other than classical (IR) genes may be responsible for MHC disease associations in this model. (J. Clin. Invest. 1993. 91:2761-2768.) Key words: systemic lupus erythematosus • autoantibody $\bullet$ major histocompatibility complex $\bullet$ murine models $\bullet$ immune response genes
\end{abstract}

\section{Introduction}

Susceptibility to many autoimmune diseases is influenced by genes of the MHC (reviewed in reference 1). For human SLE, certain alleles of genes encoded by the HLA DR, DP, DQ, and $\mathrm{C} 4$ loci result in enhanced risk of disease and may be associated with particular autoantibody specificities (1-4). In murine SLE, data also indicate an association between MHC alleles and disease. In the (NZB $\times$ NZW) F1 model, H-2 is one of several genetic loci that contribute to disease severity (5). For NZB mice $\left(\mathrm{H}-2^{\mathrm{d}}\right)$, the substitution of the $\mathrm{H}-2^{\mathrm{bm} 12}$, but not the $\mathrm{H}-2^{b}$, haplotype results in production of greater levels of antibody to double- and single-stranded DNA (dsDNA and

E. Creech and D. Nakul-Aquaronne made equal contributions to this work.

Address correspondence and reprint requests to Dr. Philip L. Cohen, CB\#7280, 932 FLOB, University of North Carolina School of Medicine, Chapel Hill, NC 27599-7280.

Received for publication 14 September 1992 and in revised form 22 January 1993.

J. Clin. Invest.

(C) The American Society for Clinical Investigation, Inc.

$0021-9738 / 93 / 06 / 2761 / 08 \$ 2.00$

Volume 91, June 1993, 2761-2768
ssDNA, respectively $)^{1}$, and to a shortened lifespan due to glomerulonephritis (6). In addition, the autoimmune disease of the BXSB mouse is less severe in animals expressing $\mathrm{H}-2^{\mathrm{d}}$ instead of the $\mathrm{H}-2^{\mathrm{b}}$ allele normally present in this strain (7).

The autosomal recessive $l p r$ gene, recently demonstrated to be a nonexpressed mutant form of the Fas apoptosis-inducing cell surface receptor (8), causes lymphadenopathy and autoantibody formation. The nature and severity of disease are dependent on background genes (9), and lpr accelerates any underlying autoimmune proclivity. For example, MRL/Mp-lpr/lpr mice develop massive lymphadenopathy; antibodies to multiple autoantigens including dsDNA, ssDNA, chromatin, IgG, $\mathrm{Su}$, ribosomal $\mathrm{P}$ protein, and $\mathrm{Sm}$, as well as severe renal disease. In contrast, C57BL/6-lpr/lpr (B6/lpr) mice develop more modest lymphadenopathy and antibodies to chromatin, ssDNA, and IgG (9), but fail to develop antibodies to Sm or dsDNA, and do not have vasculitis or renal disease. Intercross analysis has shown that multiple background genes are responsible for the differences in the lpr-induced autoimmunity, and it has thus far not been possible to demonstrate an MHC effect on renal disease or autoantibody production (10). We have, therefore, sought a system free of the influence of other genetic differences to study the effects of MHC genes on systemic autoimmunity. We thus took advantage of the existence of $\mathrm{H}-2$ congenic C57BL/ 6 strains to derive new lpr strains that differ only at MHC loci. The results indicated that substitution of the $\mathrm{H}-2^{\mathrm{d}}$ allele for $\mathrm{H}-2^{\mathrm{b}}$ resulted in diminished autoimmunity, but that $\mathrm{H}-2^{\mathrm{bm} 12}$ did not influence autoantibody production. Surprisingly, the reduction in autoimmunity observed in B6/lpr$\mathrm{H}-2^{\mathrm{d}}$ reflected a generalized lowering of autoantibody production rather than an effect on autoantibody fine specificity.

\section{Methods}

Mice. C57BL/6 (B6) and C57BL/6-lpr/lpr (B6/lpr) mice (H-2 $\left.{ }^{\mathrm{b}}\right)$; and HW19 (H-2 ${ }^{d}$-congenic B6) mice were originally obtained from the Jackson Laboratory (Bar Harbor, ME) and maintained in our breeding colony at the University of North Carolina at Chapel Hill. B6.C-H-2 ${ }^{\text {bm } 12}(\mathrm{bm} 12)$ mice were originally obtained from Dr. Roger Melvold, Northwestern University (Evanston, IL) and have been bred in our colony.

To produce $\mathrm{H}-2^{\mathrm{d}}$-congenic $\mathrm{B} 6 / \mathrm{lpr}$ mice, we crossed $\mathrm{B} 6 / \mathrm{lpr}$ and HW19. F1 hybrid mice were intercrossed, and the F2 generation was screened for lpr homozygosity by assessing antichromatin autoantibodies and rheumatoid factors by ELISA. H-2 phenotype was determined by immunofluorescence using AF6-88.5.3 (anti-H-2K ${ }^{\text {b }}$ ) and SF1-1.1.1 (anti-H-2K $\mathrm{K}^{\mathrm{d}}$ ), both from American Type Culture Collection, (Rock-

1. Abbreviations used in this paper: BBS, borate-buffered saline; dsDNA, double-stranded DNA; EDF, equivalent dilution factor; HGG, human gamma globulin; IR, immune response; KLH, keyhole limpet hemocyanin; ssDNA, single-stranded DNA. 
ville, MD). To obtain $\mathrm{H}-2^{\mathrm{d}}$ homozygous founder mice, it was necessary to intercross one more generation. The $\mathrm{B} 6 / \mathrm{lpr} . \mathrm{H}-2^{\mathrm{d}}$ mice were also crossed to $\mathrm{B} 6 / \mathrm{lpr}$, and the $\mathrm{F} 2$ generation was tested for segregation of $\mathrm{H}-2$ phenotype and autoantibody levels (see text).

To produce the B6/lpr.H-2 ${ }^{\mathrm{bm} 12}$ strain, B6/lpr was mated to bm 12 , and $F 2$ mice screened in a fashion analogous to that described above. Typing for $\mathbf{I}-\mathrm{A}^{\mathbf{b}}$ was accomplished by immunofluorescence using D3137.5 (anti-I- $\left.\mathrm{A}^{\mathrm{b}}\right)$; as there is no $\mathrm{I}-\mathrm{A}^{\mathrm{bm} 12}$-specific reagent generally available, bm 12 mice were identified by their lack of $\mathrm{Ia}^{\mathrm{b}}$. Additional intercrosses were necessary to generate $\mathrm{B} 6 / \mathrm{lpr} . \mathrm{H}-2^{\mathrm{bm} / 2}$ homozygous founder mice. The identity of $\mathrm{B} 6 / \mathrm{lpr} . \mathrm{H}-2^{\mathrm{bm} 12}$ mice was also confirmed by their characteristic response to immunization with insulin (11).

IgG antichromatin. Chromatin Ag was purified from chicken erythrocyte nuclei (12). Polyvinyl chloride microtiter plates (Dynatech Laboratories, Inc., Chantilly, VA) were coated with $100 \mu \mathrm{l}$ of a $3-\mu \mathrm{g} / \mathrm{ml}$

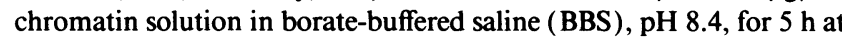
$4^{\circ} \mathrm{C}$. After washing with BBS and incubating with $200 \mu \mathrm{l}$ of coating buffer (BBS, $0.5 \%$ BSA, $0.4 \%$ Tween 80 ) for $1 \mathrm{~h}$ at $4^{\circ} \mathrm{C}$, serum samples (diluted $1 / 500$ in coating buffer) were added. After overnight incubation at $4^{\circ} \mathrm{C}$, the plates were washed five times with $\mathrm{BBS}$, and a $1 / 2,000$ dilution of biotinylated affinity-purified goat anti-mouse $\mathrm{IgG}\left(\mathrm{pFc}^{\prime}\right.$ specific) was added for $1 \mathrm{~h}$ at $4^{\circ} \mathrm{C}$. After washing, the plates were incubated with avidin-alkaline phosphatase (Zymed Labs, Inc., South San Francisco, CA) for $1 \mathrm{~h}$ at $4^{\circ} \mathrm{C}$. After further washing, phosphatase substrate (Sigma Chemical Co., St. Louis, MO) was added in $0.01 \mathrm{M}$ diethanolamine, $\mathrm{pH} 9.8$, to each well. The plates were read with an automated micro-ELISA reader at 1,3 , and $24 \mathrm{~h}$ after substrate addition. A standard curve was constructed using a high titer MRL/lpr mouse serum, and EDF (equivalent dilution factor) values were calculated according to the following formula: $E D F=$ (dilution of standard reference sera that gives the equivalent $O D$ of the test serum) $\times 10^{6}$. The standard dilution curves were usually linear and not steep in the OD range tested.

Anti-ssDNA. Calf thymus DNA (Sigma Diagnostics Co, St. Louis, MO) was denatured at $100^{\circ} \mathrm{C}$ for $10 \mathrm{~min}$, and $100 \mu \mathrm{l}$ of a $10-\mu \mathrm{g} / \mathrm{ml}$ solution of ssDNA was added to each well. The antibodies were detected with a biotinylated affinity-purified rat anti-mouse $\kappa$ monoclonal antibody. A high titer MRL/lpr mouse serum was used for the standard curve.

Anti-dsDNA. The indirect fluorescent antibody procedure for the detection of anti-dsDNA antibodies was performed with substrate slides of Crithidia luciliae (Kallestad Diagnostics, Inc., Chaska, MN). The serum samples diluted $1 / 10$ were incubated $30 \mathrm{~min}$ in a moist box. After washing with PBS, anti-dsDNA antibodies bound to the Crithidia kinetoplast DNA were detected with a rabbit anti-mouse IgG linked to a fluorochrome (FITC). $30 \mathrm{~min}$ later, the slides were read using a fluorescence microscope at a magnification of 400. An anti-dsDNA positive MRL/lpr hybridoma and an anti-dsDNA negative tissue culture supernatant were used as controls.

Rheumatoid factors and total IgM. Rheumatoid factor and total serum IgM were tested in assays similar to those described above. The plates were coated with monoclonal reagents rendered free of IgM by previous absorption. Myeloma proteins used as antigen for detection of isotype specific rheumatoid factors were as listed in (13) except for $\mathrm{IgG1}^{\mathrm{a}}$ (HB57) and the $\operatorname{IgG}_{2} \mathrm{a}^{\mathrm{a}}$ (P1.17). Antibodies to these platebound IgGs were detected with biotinylated affinity-purified Bet-2 rat anti-mouse IgM $F\left(a b^{\prime}\right)_{2}$, followed by avidin-alkaline phosphatase and substrate.

Immunizations. Mice were given $50 \mu \mathrm{g}$ of human gamma globulin (HGG) purified from Cohn Fraction II of human serum or keyhole limpet hemocyanin (KLH) (Sigma Chemical Co.) subcutaneously in CFA. They were boosted with $50 \mu \mathrm{g}$ of antigen in incomplete Freund's adjuvant $10 \mathrm{~d}$ later, and were tail-bled $1 \mathrm{wk}$ later ( $17 \mathrm{~d}$ after immunization).

$H G G$ and KLH ELISAs. IgG antibodies to HGG and KLH were quantitated by coating microtiter wells with $3 \mu \mathrm{g} / \mathrm{ml}$ of protein antigen in BBS. The plates were then processed as above. Serum was added at a
$1 / 200$ dilution. Bound antibody was detected using biotinylated goat anti-mouse IgG.

Immunoblotting. Chicken erythrocyte chromatin was dissolved at $0.55 \mathrm{mg} / \mathrm{ml}$ in Laemmli buffer containing bromphenol blue, sodium phosphate, glycerol, SDS, water, and DTT. After heating for $3 \mathrm{~min}$ at $100^{\circ} \mathrm{C}$, the diluted sample and $5 \mu \mathrm{l}$ of prestained molecular mass protein standards, 3,000-43,000 D, (Gibco BRL, Gaithersburg, MD) were electrophoresed on a 10-20\% gradient polyacrylamide gel with SDS. The electrophoresis was performed at $20 \mathrm{~mA}$ for $2.5 \mathrm{~h}$. The separated polypeptides were transferred to nitrocellulose paper by electroblotting in transfer buffer ( $25 \mathrm{mM}$ Tris hydroxide, $192 \mathrm{mM}$ glycine, $20 \%$ metha$\mathrm{nol}$ ) at $100 \mathrm{~V}$ for $45 \mathrm{~min}$ on ice. Nitrocellulose paper was then cut into strips and pressed overnight. The next day, the strips were incubated with Tris-buffered saline 5\% milk for $1 \mathrm{~h}$. After washing, the serum samples, diluted $3 \mu \mathrm{l} / \mathrm{ml}$ in TBS, were added. After overnight incubation, the antibodies were detected with biotinylated affinity-purified rat anti-mouse $\kappa$ diluted $1 / 1,000$, followed by avidin-alkaline phosphatase. Antibody binding was visualized using nitroblue tetrazoliumbromo-chloro-indolyl phosphate, Sigma Chemical Co.

Measurement of proteinuria. Protein was estimated in spot urines from F2 mice (Albustix; Miles Inc., Elkhart, IN). Protein concentration in the urine was classified according to five categories $(0-4+)$.

\section{Results}

Antichromatin in MHC congenic lpr mice. Antichromatin antibodies were quantitated by ELISA in sera from B6/lpr and B6/lpr.H-2 ${ }^{\mathrm{d}}$ mice at 5 mo of age. In Fig. $1 a$, it can be seen that antichromatin levels in the $\mathrm{H}-2^{\mathrm{d}}$ mice were lower than those measured in samples from $\mathrm{H}-2^{\mathrm{b}}$ individuals $(P<0.001$ for comparison of pooled male and female samples of each strain by Student's $t$ test). B6/lpr female mice had significantly higher levels of antichromatin than males $(P=0.0001)$, but there was no sex difference in antichromatin levels for B6/ lpr.H-2 ${ }^{\mathrm{d}}(P=0.8)$.

To ensure that the differences observed between the $\mathrm{B} 6 / \mathrm{lpr}$ and $\mathrm{B} 6 / \mathrm{lpr} . \mathrm{H}-2^{\mathrm{d}}$ mice segregated with $\mathrm{H}-2$, we mated $\mathrm{B} 6 / \mathrm{lpr}$ and $\mathrm{B} 6 / \mathrm{lpr} . \mathrm{H}-2^{\mathrm{d}}$ mice and intercrossed the $\mathrm{F} 1$ offspring. In the F2 generation, there were $28 \mathrm{H}-2^{\mathrm{b} / \mathrm{b}}$ mice, $43 \mathrm{H}-2^{\mathrm{b} / \mathrm{d}}$ mice, and $24 \mathrm{H}-2^{\mathrm{d} / \mathrm{d}}$ mice. As shown in Fig. $1 \mathrm{~b}$, sera from the bb mice contained significantly more antichromatin antibodies than sera from dd individuals $(P<0.001)$. Antichromatin levels in bd mice were not significantly different from those of dd mice $(P=0.71)$.

Fig. 2 shows a comparison of antichromatin determinations on the sera of $\mathrm{B} 6 / \mathrm{lpr} . \mathrm{H}-2^{\mathrm{bm} 12}$ and $\mathrm{B} 6 / \mathrm{lpr}$ mice. In contrast to what was observed for $B 6 /$ lpr.H-2 ${ }^{d}$, there was no significant difference in antichromatin between B6/lpr.H-2 ${ }^{\mathrm{bm} 12}$ and B6/lpr.

Immunoblot analysis of antichromatin in lpr strains. The ELISA results thus indicated significant differences between $\mathrm{B} 6 / \mathrm{lpr}$ and $\mathrm{B} 6 / \mathrm{lpr} . \mathrm{H}-2^{\mathrm{d}}$, but not between $\mathrm{B} 6 / \mathrm{lpr}$ and $\mathrm{B} 6 /$ lpr.H-2 ${ }^{\mathrm{bm} 12}$. It was possible that the difference observed in the former case was caused by the absence of reactivity to one of the histone components of chromatin, with preservation of reactivity to the remaining histone constituents of this antigen. To approach this question, serum samples from B6/lpr, B6/ lpr.H-2 ${ }^{d}$, and B6/lpr.H-2 ${ }^{\text {bm } 12}$ mice with high levels of antichromatin reactivity by ELISA were selected for further analysis by immunoblotting. Western blot results (Fig. 3 ) indicated that the antichromatin reactivity of $\mathrm{B} 6 / \mathrm{lpr} . \mathrm{H}-2^{\mathrm{d}}$ mice was generally directed to the same histone components recognized by 

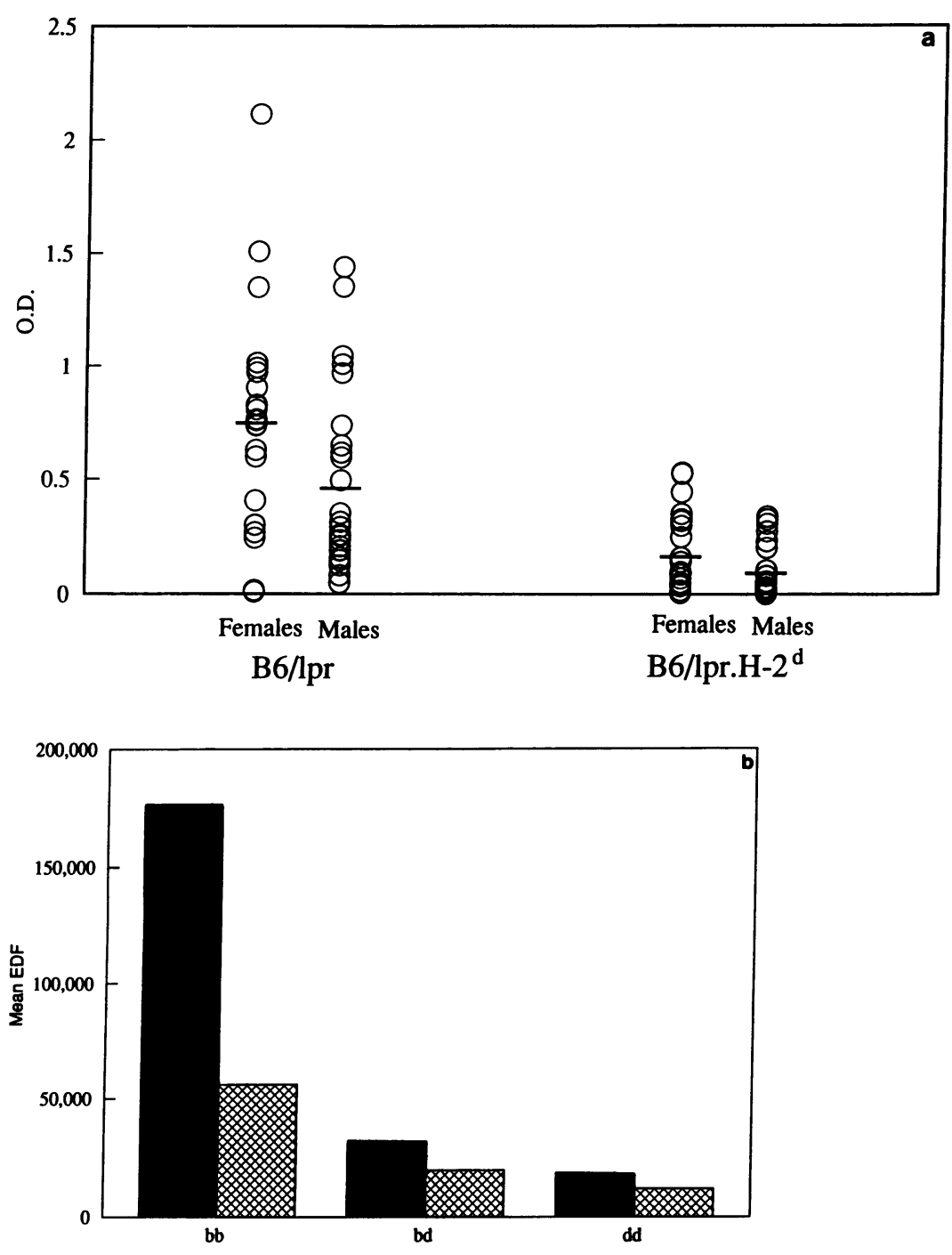

Figure 1. Antichromatin antibody distribution in B6/ $\mathrm{lpr}$ and in $\mathrm{B} 6 / \mathrm{lpr}-\mathrm{H}-2^{\mathrm{d}}$ sera. (a) Each point represents the ELISA optical density value of an individual sample taken at $5 \mathrm{mo}$ of age. The numbers of $\mathrm{B} 6 / \mathrm{lpr}$ and B6/lpr-H-2 ${ }^{\mathrm{d}}$ mice studied were: 49 ( 26 males and 23 females) and 50 ( 25 males and 25 females), respectively. (b) Antichromatin EDF levels for a cohort of F2(bb), F2(bd) and F2(dd) mice. The results were standardized against a high titer MRL/lpr mouse, so that antichromatin EDF titers could be calculated. $₫$, females; $\mathbf{a}$, males.

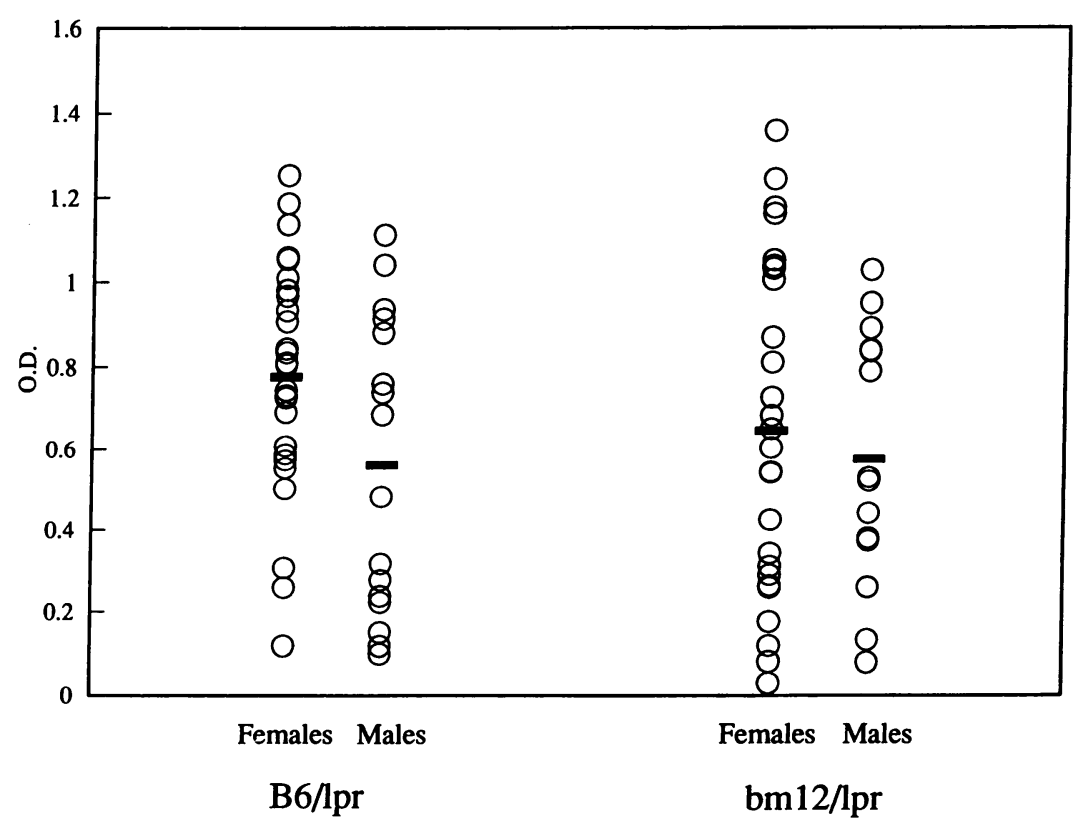

Figure 2. Antichromatin antibody distribution in B6/ lpr and B6/lpr.H-2 ${ }^{\mathrm{bm} 12}$ mice. Each point represents an individual mouse, 4-6 mo old. 42 sex- and agematched ( 16 males and 26 females) B6/lpr and B6/ lpr.H-2 ${ }^{\text {bm12 }}$ mice were studied. No significant differences between $\mathrm{B} 6 / \mathrm{lpr}$ and $\mathrm{B} 6 / \mathrm{lpr} . \mathrm{H}-2^{\mathrm{bm} 12}$ were noted. 

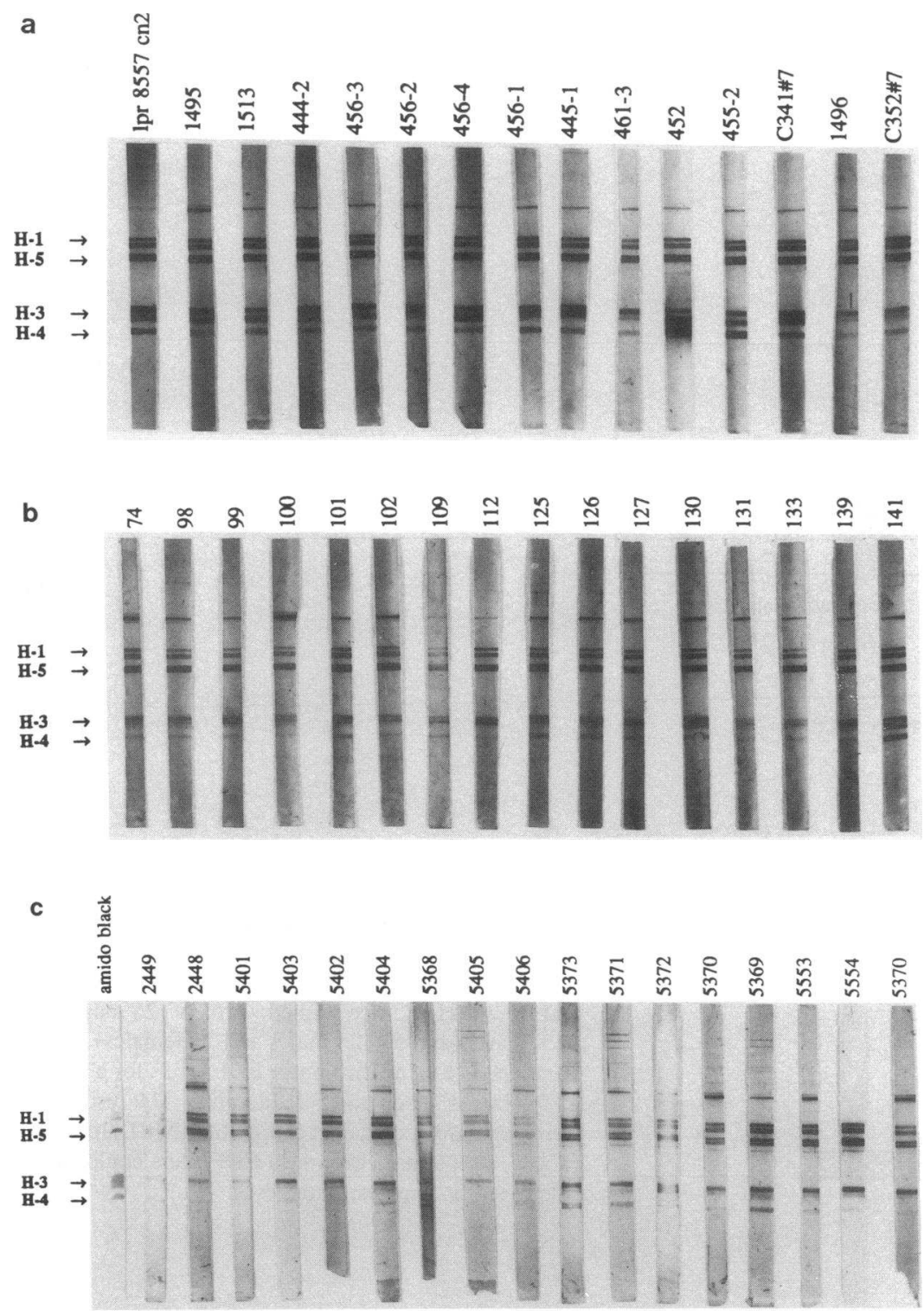

Figure 3. Western blots of antihistone antibodies. Results are for individual sera from 5 -mo-old mice (diluted $1 / 333$ ). Histones $\mathrm{H} 2 \mathrm{~B}$ and $\mathrm{H} 2 \mathrm{~A}$ run closely together, just below H3. ( $a$ ) The extreme left lane ( $l p r$ $8557 \mathrm{cn} 2$ ) shows serum from a 5-mo-old MRL/lpr mouse; the remaining sera are from $\mathrm{B} 6 / \mathrm{lpr}$ individuals. (b) $\mathbf{B} 6 /$ lpr.H-2 ${ }^{\mathrm{d}}$ sera. (c) $\mathrm{B} 6 / \mathrm{lpr} . \mathrm{H}-2^{\text {bm } 12}$ sera. Amido black staining to identify total proteins has been included for the blots in Fig. $3 C$.
B6/lpr sera, with no selective reduction in reactivity to a single histone or group of histones. These sera were selected for high antichromatin levels, thus the immunoblots show no difference in staining intensity between strains. Because there was no difference in the distribution of antibody directed toward the histone components of chromatin in B6/lpr.H- ${ }^{\mathrm{d}}$ sera, the decreased overall reactivity of these sera was caused by a generalized reduction in autoantibodies to several components of chromatin. Fig. 3 also shows immunoblot results from representative B6/lpr.H-2 ${ }^{\text {bm } 12}$ sera. These sera showed patterns similar to what was seen with B6/lpr sera. Therefore, the equivalent ELISA results did not mask a difference in antichromatin specificity.

Anti-DNA in MHC-congenic lpr mice. As was seen for antichromatin, anti-DNA titers were significantly lower in $l p r$ mice expressing the $d$ haplotype. This was ascertained by comparing anti-ssDNA levels in a cohort of parental B6/lpr and B6/lpr.H-2d individuals (not shown). The data were confirmed in an analysis of F2 mice (Fig. $4 a$ ). Those mice which inherited the dd and bd haplotypes had significantly lower lev- els of anti-DNA than bb individuals $(P<0.05)$. In contrast to these results, B6/lpr.H-2 ${ }^{\text {bm12 }}$ mice showed anti-DNA levels that were similar to those of B6/lpr. As seen in Fig. $4 b$, although there was a modest decrease in the female B6/lpr.H$2^{\mathrm{bm} 12}$ mice, this did not achieve statistical significance. We also measured anti-dsDNA in B6/lpr.H- $-2^{\mathrm{d}}$ and B6/lpr.H-2 ${ }^{\mathrm{bm} 12}$. None of these strains showed any positivity in the Crithidia luciliae immunofluorescence assay.

Rheumatoid factor levels in congenic lpr mice. B6/lpr mice are known to produce substantial amounts of rheumatoid factor (14). We determined the effect of MHC haplotype substitutions on the amount and specificity of this autoantibody. Rheumatoid factor in parental B6/lpr mice was present in significantly higher levels than in $\mathrm{B} 6 / \mathrm{lpr} . \mathrm{H}-2^{\mathrm{d}}$ animals (data not shown). As was done for the other autoantibody measurements, results were confirmed in F2 mice. Fig. $5 a$ shows that IgM anti-IgG $1^{b}$ levels were markedly lower in bd and dd mice. The same was true for anti-IgG2 $b^{\text {b }}$ (Fig. $5 b$ ). Levels in bd mice were not significantly different from those measured in dd animals. In contrast to these data, there was no difference between 

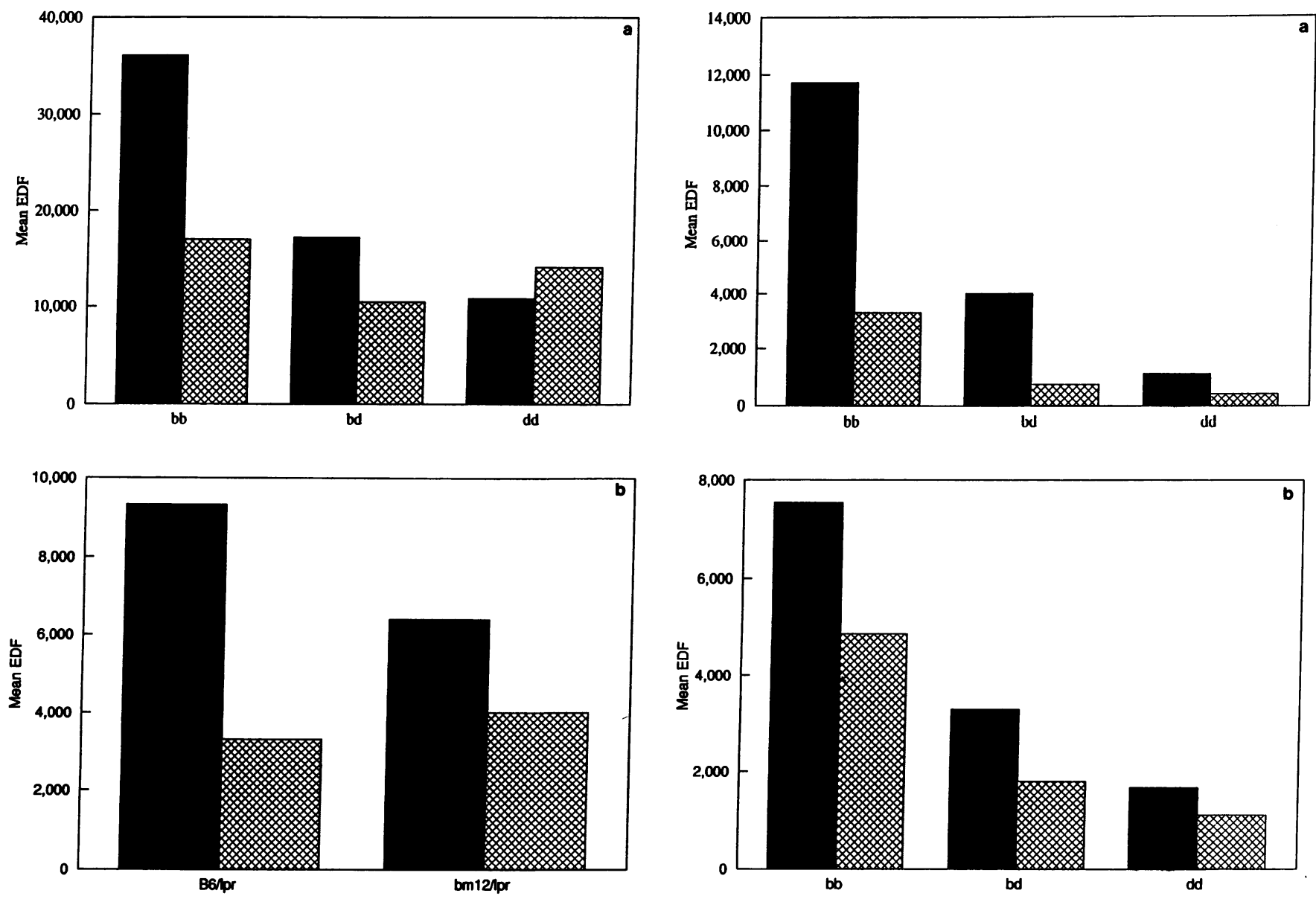

Figure 4. (a) Anti-ssDNA antibody levels $(E D F)$ in the same cohort of $\mathrm{F} 2$ mice used for antichromatin measurements shown in Fig. 1. $\mathrm{H}-2^{\mathrm{b}}$ mice showed a greater level of anti-ssDNA antibody compared to $\mathrm{H}-2^{\mathrm{d}}(P<0.001)$ and $\mathrm{H}-2^{\mathrm{b} / \mathrm{d}}$ mice $(P<0.001)$. (b) Anti-ssDNA EDF titers in B6/lpr and B6/lpr.H-2 ${ }^{\text {bm } 12}$ mice. The differences observed were not significant $(P>0.05)$. $₫$, females; $\square$, males.

$\mathrm{B} 6 / \mathrm{lpr}$ and $\mathrm{B} 6 / \mathrm{lpr} . \mathrm{H}-2^{\mathrm{bm} 12}$ rheumatoid factor titers against the $\mathrm{IgG} 1 \mathrm{~b}$ and $\mathrm{IgG} 2 \mathrm{~b}$ isotypes (Fig. 6). In an effort to discern differences in rheumatoid factor fine specificity between $\mathrm{B} 6 / \mathrm{lpr}$ and $\mathrm{B} 6 / \mathrm{lpr} . \mathrm{H}-2^{\mathrm{bm} 12}$, we measured IgM antibody against both a and $b$ allotype myeloma proteins representing all of the murine subclasses (Fig. 6). There were no differences between the two strains.

Responsiveness of congenic lpr mice to immunization. It was possible that the lower autoantibody levels in B6/lpr.H-2 ${ }^{\mathrm{d}}$ mice reflect a generalized decreased responsiveness to antigenic stimulation. This question was approached by assessing antibody responses to HGG and KLH. As seen in Table I, there was no difference between $\mathrm{B} 6 / \mathrm{lpr}$ and $\mathrm{B} 6 / \mathrm{lpr} . \mathrm{H}-2^{\mathrm{d}}$ mice in antibody levels after immunization.

Other studies in MHC-congenic lpr strains. We compared the total spleen and lymph node weights of 7-mo-old MHCcongenic lpr mice (Table II). Spleen and lymph node weights of $\mathrm{F} 2 \mathrm{bb}$ homozygous mice were significantly greater than those observed for dd mice $(P=0.006$ and 0.02 for spleen and lymph nodes, respectively). For bb vs bd mice, differences approached statistical significance for spleen $(P=0.07)$ but not for lymph node $(P=0.21)$. When bd mice were compared with dd homozygotes, on the other hand, lymph node weights

Figure 5. Isotype-specific rheumatoid factors directed against $\operatorname{IgG} 1^{\mathbf{b}}$ $(a)$ and $\operatorname{IgG} 2 \mathrm{~b}^{\mathrm{b}}(b)$ in F2 (bb), F2 (bd), and F2(dd) mice. H-2 ${ }^{\mathrm{b}}$ homozygous mice were significantly different from $\mathrm{B} 6 / \mathrm{lpr}-\mathrm{H}-2^{\mathrm{d}}$ and from F2 (bd) for both specificities $(P<0.001)$. $₫$, females; $\square$, males.

were significantly greater in the bd mice $(P=0.04)$, yet spleen weights were not significantly different $(P=0.14)$.

We also tested for proteinuria in female mice of these strains using the semiquantitative Albustix method and found

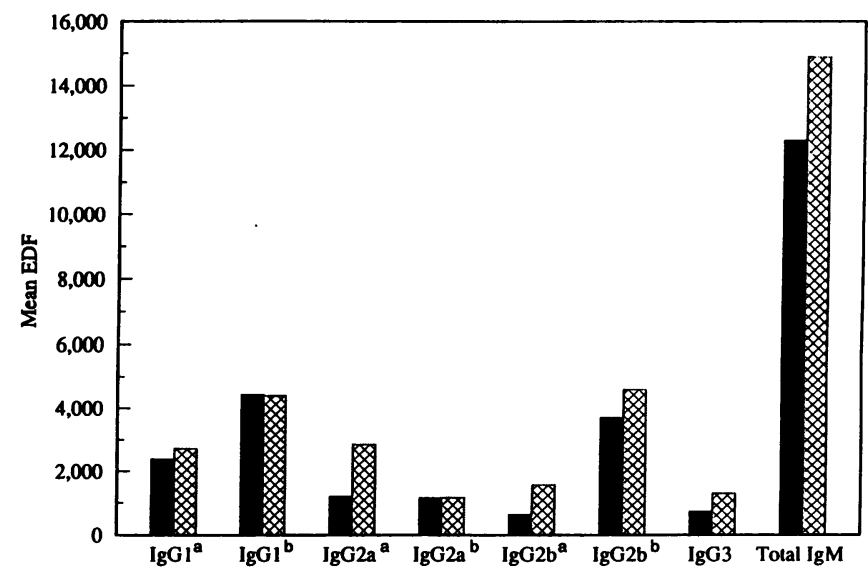

Figure 6. IgG subclass and allotype-specific rheumatoid factors and total IgM in B6/lpr vs B6/lpr.H-2 ${ }^{\mathrm{bm} 12}$ mice. For each rheumatoid factor specificity, B6/lpr and B6/lpr.H-2 ${ }^{\mathrm{bm} 12}$ mice were not different $(P>0.1) . \pm$, B6/lpr;, \pm bm $12 / \mathrm{lpr}$. 
Table I. Responses of B6/lpr and B6/lpr.H-2d Mice to Immunization

\begin{tabular}{lcccc}
\hline \multicolumn{1}{c}{ Strain } & $\begin{array}{c}\text { No. of } \\
\text { mice }\end{array}$ & Antigen & $\begin{array}{c}\text { Prebleed } \\
\text { OD (SD) }\end{array}$ & 4-wk OD \\
\hline B6/lpr & 7 & HGG & $0.024(0.022)$ & $0.409(0.102)$ \\
B6/lpr.H-2 & 5 & HGG & $0.076(0.042)$ & $0.464(0.068)$ \\
B6/lpr & 7 & KLH & $0.046(0.009)$ & $0.160(0.047)$ \\
B6/lpr.H-2 ${ }^{\text {d }}$ & 6 & KLH & $0.039(0.005)$ & $0.146(0.020)$
\end{tabular}

Three month old mice of both sexes were immunized subcutaneously with $50 \mu \mathrm{g}$ of antigen in CFA, followed $10 \mathrm{~d}$ later by a booster immunization of $50 \mu \mathrm{g}$ of antigen in incomplete Freund's adjuvant. Mice were bled $17 \mathrm{~d}$ after initial immunization, and sera were tested at a dilution of $1 / 200$ in ELISA.

no significant urinary protein in any of the mice. Finally, we measured anti-Sm autoantibodies by ELISA, and found no positive sera.

\section{Discussion}

We have created two congenic B6/lpr mouse strains: B6/ lpr. $\mathrm{H}-2^{\mathrm{d}}$, which expresses the $\mathrm{d}$ allele of the $\mathrm{H}-2$ complex in place of the $b$ allele expressed by B6/lpr; and B6/lpr.H-2 ${ }^{\mathrm{bm} 12}$, which is identical to $\mathrm{B} 6 / \mathrm{lpr}$, except that it expresses the bm 12 mutation at I-A $\beta$. B6/lpr.H-2 ${ }^{\mathrm{d}}$ mice had substantially lower levels of spontaneous autoantibodies to chromatin, single stranded DNA, and mouse IgG. In contrast, B6/lpr.H-2 ${ }^{\text {bm } 12}$ mice were identical to $\mathrm{B} 6 / \mathrm{lpr}$ mice in these assays.

The present data are consistent with earlier reports in the NZB/NZW and NZB/SWR models implicating an MHC gene effect on systemic autoimmunity $(5,15)$. The results differ, however, from findings of an exacerbating effect of the bm 12 I-A phenotype on NZB autoimmune disease (6). It has been suggested that the acceleration of autoimmunity imposed by the bm 12 haplotype may be caused by an amino acid substitution at position 72 of I-A $\beta$, a position also implicated as the possible locus of the NZW contribution to the autoimmunity of NZB/NZW (6). The present results indicate that the bm 12 effect on NZB is not generalizable to all strains. Our data also differ in that the NZB $\left(\mathrm{H}-2^{\mathrm{d}}\right)$ and NZB.H-2 ${ }^{\mathrm{b}}$ showed similar levels of autoantibodies. The differences between our findings and the effects of different $\mathrm{H}-2$ haplotypes on NZB are likely to

Table II. Lymph Node and Spleen Weights in MHC Congenic lpr Mice

\begin{tabular}{cccc}
\hline $\begin{array}{c}\text { H-2 } \\
\text { haplotype }\end{array}$ & $\begin{array}{c}\text { Number } \\
\text { of Mice }\end{array}$ & $\begin{array}{c}\text { Lymph Node } \\
\text { Weight (SD) }\end{array}$ & $\begin{array}{c}\text { Spleen } \\
\text { weight (SD) }\end{array}$ \\
\hline & & $g$ & \\
bb & 27 & $1.310(1.191)$ & $0.315(0.196)$ \\
bd & 43 & $1.022(0.698)$ & $0.221(0.208)$ \\
dd & 23 & $0.669(0.554)$ & $0.154(0.077)$
\end{tabular}

(B6/lpr.H-2 ${ }^{\mathrm{d}} \times \mathrm{B} 6 / \mathrm{lpr}$ ) F2 mice were typed by immunofluorescence staining. At $7 \mathrm{mo}$ of age, they were sacrificed and the weight of the spleen and the total weight of the cervical, axillary, paraaortic, inguinal, and mesenteric lymph nodes were determined. be caused by the many genetic differences between NZB and the B6/lpr model, for instance at the level of $\mathrm{T}$ cell receptor repertoire.

H-2 haplotype has recently been shown to affect the systemic autoimmune disease of BXSB mice (7). The substitution of $\mathrm{H}-2^{d}$ for the $\mathrm{H}-2^{b}$ haplotype led to decreased autoantibody production, diminished glomerulonephritis, and enhanced survival. These results are analogous to ours, and may reflect the similarities in background genes between B6 and the related BXSB strain.

It is possible that the observed differences in autoantibody production by lpr strains with different MHC haplotypes are caused by the allelic differences in class II MHC gene function, analogous to the classic experiments demonstrating Ia control of the response to exogenous antigens. This interpretation would fit well into current paradigms of immunology. Like exogenous antigens, autoantigens could be regarded as polypeptides that undergo processing and ultimately bind to surface class II MHC antigens for presentation to T cells. In fact, in the immune response (IR) gene literature, there is precedent for immune responses to modified self antigens such as albumin or IgA under such MHC-linked gene control (16). Allelic Ia polymorphisms might thus reflect the different efficiencies with which certain Ia antigens bind peptides processed from particular autoantigens. The molecular basis of this phenomenon is widely believed to be the three-dimensional structure of an antigen-binding groove demonstrated on the exterior of $\mathrm{MHC}$ molecules. It is also possible that the MHC-determined differences in autoantibody production reflect differences in the $\mathrm{T}$ cell repertoire that develops in the presence of the $\mathrm{MHC} \mathrm{b}$ haplotype versus the $\mathrm{d}$ haplotype, or that the MHC differences result in altered immune response because of suppressor cell activity. Both of these latter mechanisms have been proposed as explanations of classic MHC-linked IR gene phenomena (17). The greater lymph node and spleen size of the b haplotype mice, compared to the $d$ haplotype individuals, might reflect a more intense $\mathrm{T}$ cell immune response in the former, with consequent generation of increased numbers of double negative cells, or might be caused by interstrain differences in $\mathrm{T}$ cell repertoire.

The observations concerning the $\mathrm{d}$ haplotype might alternatively be explained by the expression in this haplotype of I-E molecules, which are not expressed in B6/lpr or B6/lpr.H$2^{\mathrm{bm} 12}$ because of the nonfunctional $\mathrm{E} \alpha$ gene of the $\mathrm{b}$ haplotype. Such a mechanism would imply a suppressive effect of I-E expression on autoimmunity, similar to the effect of I-E on autoimmune diabetes in the non-obese diabetic model (18, 19), and on mercuric chloride-induced antinucleolar antibodies (20). A potential finding of importance to these studies is the recent observation that I-E-derived peptides may be detected bound to purified I-A molecules (21). Mice expressing I-E may thus generate peptides that bind to their surface I-A and undermine its capacity to bind other peptides, perhaps reducing immune responses. Any suppressive effect of I-E, while of potential importance in the preceding models, clearly would not be sufficient to alleviate systemic autoimmune disease in all cases, as severe autoimmunity is seen in the I-E+ $(\mathrm{NZB} \times \mathrm{NZW})$ and $(\mathrm{NZB} \times \mathrm{SWR}) \mathrm{F} 1$ mice, as well as in MRL/lpr.

Nevertheless, I-E expression may well have important influences on the nature of autoimmunity by shaping of the $T$ cell 
repertoire or providing suppressive signals. In the BXSB model, it was of interest that the expression of $\mathrm{I}-\mathrm{E}$ in $\mathrm{H}-2^{\mathrm{d}}$ mice led, as expected, to the deletion of $\mathrm{T}$ cells expressing $\mathrm{V} \beta 5$ and $\mathrm{V} \beta 11$ (7). Nevertheless, it appeared unlikely that the loss of these $T$ cells was responsible for the ameliorating effect of $\mathrm{H}-2^{\mathrm{d}}$, because $\mathrm{H}-2^{\mathrm{b} / \mathrm{d}}$ mice developed a syndrome resembling that of $\mathrm{H}-2^{b}$ mice, despite the reduction in $\mathrm{V} \beta 5$ - and $\mathrm{V} \beta 11$ bearing $T$ cells. These results also argued against a generalized protective effect of I-E expression in that system. We are currently exploring the influence of I-E in our model by examining other MHC-congenic B6/lpr mice that express I-E, and by assessing autoimmunity in $\mathrm{I}-\mathrm{E}_{\alpha}{ }^{\mathrm{d}}$-transgenic $l p r$ mice.

Our data show that female individuals, particularly B6/lpr mice, produce larger amounts of autoantibodies than males. This observation is consistent with heightened systemic autoimmunity observed in females. It is possible that the increased levels of autoantibodies in the females are related to increased numbers of autoreactive $\mathrm{T}$ cells, particularly in the $\mathrm{H}-2^{\mathrm{b}}$ strain. In females, estrogens may favor extrathymic differentiation in the liver of $T$ cells with autoreactive characteristics, and thus may lead to enhanced production of autoantibodies (22).

Another interesting aspect of our data is the lack of influence of the bm 12 mutation on autoantibody levels. Although only three residues in $\mathrm{I}-\mathrm{A} \beta$ differ between $\mathrm{H}-2^{\mathrm{bm} 12}$ and $\mathrm{H}-2^{\mathrm{b}}$, these two alleles are generally associated with major differences in immune responsiveness to foreign antigens (11) and in susceptibility to experimental myasthenia gravis (23), probably because the altered amino acid residues lie within the peptide binding groove of the I-A $\beta$ chain. In addition, as discussed previously, NZB. ${ }^{\text {bm } 12}$ mice have considerably higher titers of autoantibodies than NZB.H-2 ${ }^{b}$ mice (6). It is thus surprising that $\mathrm{B} 6 / \mathrm{lpr} . \mathrm{H}-2^{\mathrm{bm} 12}$ mice and $\mathrm{B} 6 / \mathrm{lpr}$ mice have no detectable differences in autoantibody levels or in the specificities recognized by antichromatin antibodies or by rheumatoid factor.

Yet another striking aspect of the present results is the recessive nature of the high responder phenotype. In general, MHC-linked IR genes are dominant, with F1 animals manifesting responses close to homozygous responders, or at least intermediate between responders and nonresponders. We have found that the responses of $\mathrm{H}-2^{\mathrm{b} / \mathrm{d}} l p r$ mice were not significantly different from those of low responder B6/lpr.H-2 ${ }^{d}$ animals. This suggests that the influence of $\mathrm{H}$-2-linked genes on autoantibody production may not be caused by classical IR gene effects mediated by allele-specific binding to class II molecules of antigenic peptides. Our results differ from the findings in the BXSB model, where $\mathrm{F} 1 \mathrm{H}-2^{\mathrm{b} / \mathrm{d}}$ mice expressed the high autoantibody levels characteristic of their $\mathrm{H}-2^{\mathrm{b}}$ parents (7).

The general nature of the $\mathrm{H}-2^{\mathrm{d}}$ effect is also difficult to understand as a manifestation of classic IR gene effects. The low responder $d$ haplotype appears to have diminished autoantibody responses to an array of autoantigens, and not merely a single autoantigen: chromatin (consisting of multiple histones and DNA); single-stranded DNA; and rheumatoid factor directed against IgG1 and against IgG2b. In contrast, for most IR gene controlled responses, the target antigens are either simple synthetic polypeptides with limited numbers of epitopes, or are modified self antigens. IR gene phenomena are usually discrete and reciprocal; for instance, $\mathrm{H}-2^{\mathrm{b}}$ mice respond to the synthetic amino acid copolymer ( T,G)-A-L but not to the closely related $(\mathrm{H}, \mathrm{G})-\mathrm{A}-\mathrm{L}$; the reverse is true for $\mathrm{H}-2^{\mathrm{k}}$ mice (24). IR gene polymorphisms would not be expected to result in appar- ently global changes in spontaneous autoantibody production we have observed in our $\mathrm{H}-2$ congenic lpr mice, but rather in changes in the fine specificity of certain autoantibodies, with perhaps increases in some specificities, along with decreases in others. We thus suggest that other genes in the MHC complex may affect the lpr syndrome. Known genes include class I antigens, which are surface glycoproteins involved in peptide antigen binding and interaction with $\mathrm{CD}^{+} \mathrm{T}$ cells; tumor necrosis factors $\alpha$ and $\beta$, which have been reported to have a potent influence on autoimmune and inflammatory phenomena (25); C2 and C4 genes, also linked to disease susceptibility (2); the HSP 70 heat shock protein gene (26); a series of single copy genes of uncertain function (27); and an array of highly interesting recently discovered class II-linked genes that are responsible for the intracellular transport of peptides and for the degradation of protein antigens into small peptides for binding to class I and class II molecules (28). It is possible that the suppressive effect on autoantibodies resulting from the substitution of the $d$ for the $b$ MHC allele might involve any one of these non-Ia genes. For instance, autoantibody formation could be influenced by general differences in autoantigen peptide binding or binding of an autoantigen peptide, which plays a broad role in T-B collaboration; class I mediated suppressive effects; variations in peptide transporter genes or in genes controlling protein degradation $(29,30)$; or effects of yet-undiscovered genes that may also be encoded in the MHC. Recently, it has been shown that peptide transporter gene polymorphisms may influence the peptides bound by MHC genes (31). Such MHC-linked polymorphisms may prove to have clinical relevance by exerting a broad effect on antigen presentation in autoimmune disease.

\section{Acknowledgments}

We thank Robert L. Cheek for assistance with immunoblot assays.

This work was supported by U.S. Public Health Service grants AR34156, AR40620, AR26574, AR33887, AR30701, and T32 Al07273. E. Sobel is a Fellow of the Arthritis Foundation, and E. Creech is a Holderness Fellow. D. Nakul-Aquaronne received support from the Philippe Foundation.

\section{References}

1. Goldstein, R., and F. C. Arnett. 1987. The genetics of rheumatic disease in man. Rheum. Dis. Clin. North Am. 13:487-510.

2. Olsen, M. L., R. Goldstein, F. C. Arnett, M. Duvic, M. Pollack, and J. D. Reveille. 1989. C4A gene deletion and HLA associations in black Americans with systemic lupus erythematosus. Immunogenetics. 30:27-33.

3. Fujisaku, A., M. B. Frank, B. Neas, M. Reichlin, and J. B. Harley. 1990. HLA-DQ gene complementation and other histocompatibility relationships in man with the anti-Ro/SSA autoantibody response of systemic lupus erythematosus. J. Clin. Invest. 86:606-611.

4. Reveille, J. D., K. L. Anderson, R. E. Schroehenloher, R. T. Acton, and B. O. Barger. 1991. Restriction fragment length polymorphism analysis of HLADR, DQ, DP, and C4 alleles in Caucasians with systemic lupus erythematosus. $J$. Rheumatol. 18:14-18.

5. Knight, J. G., and D. D. Adams. 1978. Three genes for lupus nephritis in NZB $\times$ NZW mice. J. Exp. Med. 147:1653-1660.

6. Chiang, B. L., E. Bearer, A. Ansari, K. Dorshkind, and M. E. Gershwin 1990. The bm 12 mutation and autoantibodies to dsDNA in NZB.H-2 $2^{\mathrm{bm} 12}$ mice. J. Immunol. 145:94-101.

7. Merino, R., L. Fossati, M. Lacour, R. Lemoine, M. Higaki, and S. Izui. 1992. H-2-linked control of the Yaa gene-induced acceleration of lupus-like autoimmune disease in BXSB mice. Eur. J. Immunol. 22:295-299.

8. Watanabe-Fukunaga, R., C. I. Brannan, N. G. Copeland, N. A. Jenkins, and S. Nagata. 1992. Lymphoproliferation disorder in mice explained by defects in Fas antigen that mediates apoptosis. Nature (Lond.). 356:314-317. 
9. Cohen, P. L., and R. A. Eisenberg. 1991. Lpr and gld: single gene models of systemic autoimmunity and lymphoproliferative disease. Annu. Rev. Immunol. 9:243-269.

10. Eisenberg, R. A., Craven, S. Y., Fisher, C. L., Morris, S. C., Rapoport, R., Pisetsky, D. S., and P. L. Cohen. 1989. The genetics of autoantibody production in MRL/lpr lupus mice. Clin. Exp. Rheumatol. 7(Suppl. 3):535-540.

11. Hansen, T. H., W. D. Walsh, R. J. Rubocki, and J. A. Kapp. 1986 Responses of B6.C-H-2bm 12 to heterologous insulins show no correlation with the putative gene conversion but define $\mathrm{Ia}^{\mathrm{bm} 12}$ as functionally unique. J. Mol. Cell. Immunol. 2:359-368.

12. Fisher, C. L., R. A. Eisenberg, and P. L. Cohen. 1988. Quantitation and IgG subclass distribution of antichromatin autoantibodies in SLE mice. Clin. Immunol. Immunopathol. 46:205-213.

13. Morris, S. C., R. L. Cheek, P. L. Cohen, and R. A. Eisenberg. 1990. Autoantibodies in chronic graft versus hosts result from cognate T-B interactions. J. Exp. Med. 171:503-517.

14. Warren, R. W., S. A. Caster, J. B. Roths, E. D. Murphy, and D. S. Pisetsky. 1984. The influence of the lpr gene on B cell activation: differential antibody expression in lpr congenic mouse strains. Clin. Immunol. Immunopathol. 31:6577.

15. Ghatak, S., K. Sainis, F. L. Owen, and S. K. Datta. 1987. T-cell-receptor $\beta$ and I-A $\beta$-chain genes of normal SWR mice are linked with the development of lupus nephritis in NZB $\times$ SWR crosses. Proc. Natl. Acad. Sci. USA. 84:68506853.

16. Cohen, P. L., J. J. Ellner, and E. M. Shevach. 1977. Induction of guinea pig antibody responses in vitro. J. Immunol. 118:2034-2039.

17. Paul, W. E. 1984. Immune response genes. In Fundamental Immunology. W. E. Paul, editor. Raven Press, Ltd. New York. 439-455.

18. Nishimoto, H., H. Kikutani, K. Yamamura, and T. Kishimoto. 1987. Prevention of autoimmune insulitis by expression of I-E molecules in NOD mice. Nature (Lond.). 328:432-434.

19. Reich, E. P., R. S. Sherwin, O. Kanagawa, and C. A. Janeway, Jr. 1989. An explanation for the protective effect of the MHC class II I-E molecule in murine diabetes. Nature (Lond.). 341:326-328.

20. Mirtcheva, J., C. Pfeiffer, J. A. De Bruijn, F. Jacquesmart, and E. Gleichmann. 1989. Immunological alterations inducible by mercury compounds. III.
$\mathrm{H}-2 \mathrm{~A}$ acts as an immune response and $\mathrm{H}-2 \mathrm{E}$ as an immune "suppression" locus for $\mathrm{HgCl}_{2}$-induced antinucleolar autoantibodies. Eur. J. Immunol. 19:22572261 .

21. Rudensky, A., P. Preston-Hurlburt, B. K. Al-Ramadi, J. Rothbard, and C. A. Janeway, Jr. 1992. Truncation variants of peptides isolated from MHC class II molecules suggest sequence motifs. Nature (Lond.). 359:429-431.

22. Okuyama, R., T. Abo, S. Shuhji, T. Ohteki, K. Sugiura, A. Kusumi, and K. Kumagai. 1992. Estrogen administration activates extrathymic $T$ cell differentiation in the liver. J. Exp. Med. 175:661-669.

23. Bellone, M., N. Ostlie, S. J. Lei, X. D. Wu, and B. M. Conti Tronconi. 1991. The I-A ${ }^{\mathrm{bm} 12}$ mutation, which confers resistance to experimental myasthenia gravis, drastically affects the epitope repertoire of murine CD4+ cells sensitized to nicotinic acetylcholine receptor. J. Immunol. 147:1484-1491.

24. McDevitt, H. O., and B. Benacerraf. 1969. Genetic control of specific immune responses. Adv. Immunol. 11:31-74.

25. Inoko, H., and J. Trowsdale. 1987. Linkage of TNF genes to the HLA-B locus. Nucleic Acids Res. 15:8957-8962.

26. Milner, C. M., and R. D. Campbell. 1990. Structure and expression of the three MHC-linked HSP70 genes. Immunogenetics. 32:242-251.

27. Cho, S., M. Attaya, M. G. Brown, and J. J. Monaco. 1991. A cluster of transcribed sequences between the $\mathrm{Pb}$ and $\mathrm{Ob}$ genes of the murine major histocompatibility complex. Proc. Natl. Acad. Sci. USA. 88:5197-5201.

28. Glynne, R., S. H. Powiss, S. Beck, A. Kelly, L. A. Kerr, and J. Trowsdale. 1991. A proteasome-related gene between the two ABC transporter loci in the class II region of the human MHC. Nature (Lond.). 353:357-360.

29. Brown, M. G., J. Driscoll, and J. J. Monaco. 1991. Structural and serological similarity of MHC-linked LMP and proteasome (multicatalytic proteinase) complexes Nature (Lond.). 353:355-357.

30. Martinez, C. K., and J. J. Monaco. 1991. Homology of proteasome subunits to a major histocompatibility complex-linked LMP gene. Nature (Lond.). 353:664-667.

31. Powiss, S. J., E. V. Deverson, W. J. Coadwell, A. Ciruela, N. S. Huskisson, H. Smith, G. W. Butcher, and J. C. Howard. 1992. Effect of polymorphism of an MHC-linked transporter on the peptides assembled in a class I molecule. Nature (Lond.). 357:211-215. 